\title{
Jaime Sabines y la Biblia
}

\author{
Mónica Plasencia Saavedra \\ Universidad de La Laguna \\ Islas Canarias
}

Son conocidas las afirmaciones de Jaime Sabines sobre la Biblia, así como el hecho de que ésta hubiera influido de manera importantísima en su formación literaria, ${ }^{1}$ aunque, desde luego, hay libros de Sabines más explícitos que otros en lo que a la presencia del Antiguo Testamento se refiere. "Adán y Eva", por ejemplo, tiene su origen en el Génesis, aunque también hallemos reminiscencias del Cantar de los Cantares, como, por ejemplo, este fragmento en el cual Eva se duele de la ausencia de Adán y que nos lleva directamente al canto tercero del libro bíblico: "En mi lecho, por la noche, / busqué al amado de mi alma, / busquéle y no le hallé" (Cantar de los Cantares 3,1). Así, escribe Sabines:

- Hace tres días salió Adán y no ha vuelto. Ay, yo era feliz, yo era feliz.

He tenido miedo, no he podido dormir.

Estoy sola, ¿por qué no regresa? Salí a buscarlo pero él no estaba, lo llamé. Me asusta la noche, ¿qué puedo hacer sin él? Todo es muy grande, muy largo, sin rumbo. Estoy perdida, rodeada de cosas extrañas, ¿por qué no vuelve ya? (1962: 108).

Podemos decir, entonces, que tener en cuenta las resonancias del Antiguo Testamento resulta fundamental a la hora de hacer un análisis de la obra del poeta chiapaneco. "Andarás, te dijeron, de un sitio a

\footnotetext{
1 "Leía mucho, a lo loco, de todo, pero sobre todo un libro: la Biblia [...] La Biblia es el padre de todos los libros" (Zarebska 45).
} 
otro de la muerte / buscándote. / La vida no es fácil” (1962: 38), apunta. Como en el libro del Génesis, cuando Yahvé impreca: "Con el sudor de tu rostro comerás el pan hasta que vuelvas a la tierra, pues de ella has sido tomado; ya que polvo eres y al polvo volverás" (Génesis, $3,19)$. Y es que ya en su primer libro, Sabines se deja llevar por un casi místico concepto del hombre. ${ }^{2}$ La idea de antigüedad, de tiempo remoto, es evidente en prácticamente todos los poemas:

Lento, amargo animal que soy, que he sido, amargo desde el nudo de polvo y agua y viento que en la primera generación del hombre pedía a Dios.

$[\ldots]$

Amargo desde dentro, desde lo que no soy, - mi piel como mi lenguadesde el primer viviente, anuncio y profecía.

Lento desde hace siglos, remoto — nada hay detrás—, lejano, lejos, desconocido (1962: 11-12).

$[\ldots]$

Surgió, surgí dentro del sol al efímero viento en que amanece el día. Hombre. No sé. Sombra de Dios perdida.

Sobre el tiempo, sin Dios, sombra, su sombra todavía. Ciega, sin ojos, ciega,

\footnotetext{
${ }^{2}$ Nos viene a la memoria el poema "Barro", del chileno Enrique Lihn, coetáneo de Jaime Sabines: "Dios padre, Dios hijo, Dios espíritu santo: / tierra y agua; luego el barro que en el principio era. / Un solo sentimiento en el origen de todos: / este rencor inagotable". (Ortega 278).
} 
—no busca a nadie,

espera-

camina (1962: 13).

También en el libro del Génesis encontramos el mito del diluvio universal. En consonancia con ello, Jaime Sabines nos transmite en Tarumba:

$\mathrm{Y}$ viene el aguacero más grande de todos los tiempos

y el miedo de los rayos,

y tengo que subirme a un arca transformado en buey

para la vida dichosa que nos espera (1962: 149).

O en el poema titulado "Diluvio": "Si sigue lloviendo de este modo, habrá que construir un submarino atómico: poner en él un macho y una hembra de cada especie lunar" (1997: 412). Aún es más evidente en una composición de Poemas sueltos, cuando establece un claro paralelismo entre una noche orgiástica y la tradición bíblica del diluvio:

He aquí que estamos reunidos

en esta casa como en el Arca de Noé:

Blanca, Irene, María y otras muchachas,

Jorge, Eliseo, Óscar, Rafael...

Vamos a conocernos rápidamente

y a fornicar y a olvidarnos.

El buey, el tigre, la paloma, el lagarto y el asno, todos

juntos bebemos, y nos pisamos y nos atropellamos

en esta hora que va a hundirse en el diluvio nocturno.

Relámpagos de alcohol cortan la obscuridad de las pupilas

y los truenos y la música se golpean entre las voces desnudas.

Gira la casa y navega hacia las horas altas (1962: 261).

En cuanto al libro del Éxodo, hallamos reminiscencias del becerro de oro que construyó el pueblo huido de Egipto mientras Moisés se encontraba en el monte sellando su Alianza con Dios (Éxodo 32, 1-29). Así, escribe Sabines:

A un lado de los dioses

- porque los dioses han sido condenados a vivir entre

los hombres-

aprendiendo a montar el becerro de oro [...] (1962: 254). 
Cantemos al dinero

con el espíritu de la navidad cristiana.

No hay nada más limpio que el dinero, ni más generoso, ni más fuerte.

[...]

¡Aleluya, creyentes,

uníos en la adoración del calumniado becerro de oro

y que las hermosas ubres de su madre nos amamanten! (1983: 221-222).

Además, no deja de resultarnos curioso el hecho de que en la poesía de Jaime Sabines esté siempre presente, implícita o explícitamente, el mito de la expulsión del Paraíso, ${ }^{3}$ es decir, la aparición de la muerte en la idílica vida de Adán y Eva y, por ende, en la del resto de la humanidad: "Porque los ojos de la muerte me han visto y giran a mi alrededor cazándome, llevándome" (1962: 112), descubre aterrorizado Adán. Esta presencia de la muerte puede verse en ocasiones vestida de nostalgia, aunque la mayor parte de las veces lo haga de auténtico rencor. Como en estos versos de Poemas sueltos:

Señor del abismo, director de las sombras, guía de la víbora, padre de las tarántulas, hacedor del sueño, lumbre de la vigilia,

quemadura del ojo:

desaparece, esfúmate,

hazte a ti mismo nada,

gota de agua ahogada,

burbuja de aire en el pulmón del viento.

No le pongas a mi hijo palidez en la cara,

ni a mí me cargues las espaldas

en tu nombre sagrado y con tu piedra.

\footnotetext{
${ }^{3}$ Escribe Octavio Paz al respecto: "La caída de Adán significa la ruptura del paradisíaco presente eterno: el comienzo de la sucesión es el comienzo de la escisión. El tiempo en su continuo dividirse no hace sino repetir la escisión original, la ruptura del principio: la división del presente eterno e idéntico a sí mismo en un ayer, un hoy y un mañana, cada uno distinto, único. Ese continuo cambio es la marca de la imperfección, la señal de la Caída. Finitud, irreversibilidad y heterogeneidad son manifestaciones de imperfección: cada minuto es único y distinto porque está separado, escindido de la unidad. Historia es sinónimo de caída” (Paz: 34-35).
} 
Saca de mis venas toda la sangre

y deja en ellas el alcohol que me vuelve tu amigo (1962: 247). ${ }^{4}$

Del libro de los Proverbios también obtiene Jaime Sabines cierta inspiración temática y, sobre todo, formal. Ésta aparece especialmente en sus poemas cortos, titulados a modo de tratado filosófico o capítulo bíblico: "Del corazón del hombre", "De la esperanza", "Del dolor", "De la noche”, etcétera. En La señal, por ejemplo, leemos:

Entreteneos aquí con la esperanza.

El júbilo del día que vendrá

os germina en los ojos como una luz reciente.

Pero ese día que vendrá no ha de venir: es éste (1983: 35).

O en el poema titulado "De la muerte":

Enterradla.

Hay muchos hombres quietos, bajo tierra, que han de cuidarla.

No la dejéis aquí,

enterradla (1983: 36).

${ }^{4}$ Tal vez uno de los poetas mexicanos que de forma más certera desarrolló la expulsión del Edén y el advenimiento de la muerte fue Salvador Novo, quien escribe en un poema titulado "Elegía":

Los que tenemos una mirada culpable y amarga por donde mira la Muerte no lograda del mundo y fulge una sonrisa que se congela frente a las estatuas desnudas porque no podrá nunca cerrarse sobre los anillos de oro ni entregarse como una antorcha sobre los horizontes del Tiempo en una noche cuya aurora es solamente este mediodía que nos flagela la carne por instantes arrancados a la eternidad.

Los que hemos rodado por los siglos como una roca desprendida del Génesis sobre la hierba o entre la maleza en desenfrenada carrera para no detenernos nunca ni volver a ser lo que fuimos mientras los hombres van trabajosamente ascendiendo y brotan otras manos de sus manos para torcer el rumbo de los vientos o para tiernamente enlazarse.

(OlivioJiménez: 345-346). 
O el encabezado como "Del dolor":

Había sido escrito en el primer testamento del hombre:

No lo desprecies porque ha de enseñarte muchas cosas.

Hospédalo en tu corazón esta noche.

$\mathrm{Al}$ amanecer ha de irse. Pero no olvidarás

lo que te dijo desde la dura sombra. (1983: 35).

Ocurre lo mismo con el Eclesiastés, de idéntico contenido moral (y religioso, por supuesto) al libro de los Proverbios. Por esto es que cuando leemos en la Biblia:

Ve, come alegremente tu pan y bebe tu vino con corazón contento, pues que se agrada Dios en tus obras. Vístete en todo tiempo de blancas vestiduras y no falte el ungüento sobre tu cabeza. Goza de la vida con tu amada compañera todos los días de la fugaz vida que Dios te da bajo el sol, porque ésa es tu parte en esta vida entre los trabajos que padeces debajo del sol. Todo lo que puedas hacer, hazlo en tu pleno vigor, porque no hay en el sepulcro, adonde vas, ni obra, ni razón, ni ciencia, ni sabiduría (Eclesiastés 9, 7-10).hola

no podemos dejar de recordar los ya mencionados versos de Sabines: "Si sobrevives, si persistes, canta / sueña, emborráchate. / Es el tiempo del frío: ama, apresúrate" (1983: 206).

Otro importante asomo de los textos bíblicos en la poesía de Jaime Sabines es el del Libro de Job ("abandonado estoy, sarna de Job, paciencia mía”) (1962: 227), tal vez una de las obras más apasionantes de la literatura sapiencial bíblica. Y es que Job, como Sabines, se rebela contra la teología tradicional, contra la palabrería y contra la defensa de Dios a través de mentiras e injusticias: "Pero yo quisiera hablar al Omnipotente / y venir a cuentas con Dios, / pues vosotros sois inventores de falacias, / sois médicos que nada curáis" (Job 13, 3-4). Se niega en rotundo a aceptar una visión optimista del mundo. Su propia experiencia le abre al sufrimiento que reina en el mundo y en su vida y se da cuenta de que Dios no sólo castiga a los inocentes, también recompensa a los mezquinos. 5 "Cuando de repente una plaga trae la muerte, / Él se

\footnotetext{
5 No podemos evitar recordar uno de los poemas más célebres de León Felipe, "Pedigree", en el que el poeta, como Job, trata de elaborar una teoría mediante la cual logre explicar el porqué de la extraña relación entre Dios y el hombre:
} 
ríe de la desesperación de los inocentes. / La tierra es entregada a las manos de los impíos, / y vela el rostro de sus jueces" (Job 9, 23-24). La solución, entonces, no radica en aceptar el sufrimiento ni en arrepentirse; por esto, y al verse sin salida, Job, como Sabines, transita todos los estados de ánimo. Unas veces suplica, otras reprocha a Dios su crueldad, otras blasfema. Así, leemos en Tarumba:

Quiero que tu divina presencia, Comecaca, apuntale mi espíritu eterno.

Quiero que el coro de las estrellas cacofónicas truene (1983: 114).

Aunque quizás sean los poemas titulados "Poemas de unas horas místicas", de Poemas sueltos, donde mejor aparezca expuesto ese paralelismo que el mismo Sabines establece con Job. Así, mientras éste exclama:

\footnotetext{
Y ahora se derrama sobre mí mi alma

y me agarran días de aflicción;

de noche mis huesos son taladrados

y no descansan mis venas.

Con gran fuerza agarra mi vestido, me ciñe como la orla de mi túnica.

Me ha arrojado al fango,

y he venido a ser como el polvo y la ceniza.

¡Clamo a ti, y tú no me respondes;
}

¿Y por qué no hemos de ser la obra de un dios monstruoso e inmisericorde, [Señor Arcipreste? / Si nosotros estamos hechos de una substancia monstruosa e [inmisericorde también? /

¿por qué ha de ser piadoso nuestro dios? /

¿Quién tiene piedad entre los hombres? /

Además... ¿ ¿no es la vida una cadena de mandíbulas abiertas y devoradoras? / Y si la lombriz se traga la simiente, /la gallina a la lombriz / y el hombre a la gallina... / ¿por qué Dios no se ha de tragar también al Hombre? / ¡Gran manjar es el Hombre! / ¿No ha pensado usted nunca, Señor Arcipreste, / que bien podemos ser el alimento de un dios glotón y monstruoso... / y que estamos aquí como en un túnel descomunal y oscuro, / como en un gran esófago, / descendiendo... / descendiendo...

descendiendo lentamente, / pasando por los sórdidos, torcidos y laberínticos intestinos de la Historia?... (León Felipe 1982: 54). 
permanezco en pie, y no me haces caso!

Te has vuelto cruel para mí

y con todo el vigor de tu mano me persigues;

me alzas en alto y me haces cabalgar sobre el viento,

y una tormenta me deshace en agua.

Bien sé que me llevas a la muerte,

a la casa de reunión de todos los vivientes (Job 30, 16-24).

A su vez, Sabines manifiesta:

Bajo tus alas, en la dura sombra

que te baja a mis manos,

enclenque estoy, torcido como un árbol torcido.

He visto, he estado con gentes a quienes quiero,

me la he pasado hablando, haciendo,

aquí y allá, tratando de corregirme,

de crecer en medio de las cosas perfecto.

Pero no sé, no puedo, necesito.

A picotazos me tratas

y estoy cansado, malherido.

Tercamente, igual que un mono, estoy limpiándome, quitándome las manchas con todo y piel,

caído en tu tierra de almas (1962: 215).

Observamos en estos versos cómo, al igual que Job, Sabines ve tan de cerca su dolor que, verdaderamente, siente que Dios lo está castigando sin saber bien cuál es la razón. Ambos se sienten abandonados y, lo más importante, humillados: "Me ha arrojado al fango", grita Job. Sabines, por su parte, se lamenta ("a picotazos me tratas") y afirma sentirse "igual que un mono". En El hombre y lo divino, la filósofa española María Zambrano escribe sobre esta actitud de Job:

Y así, la soledad de Job, la soledad que sorberá hasta las heces de su cáliz el hombre de Occidente, Job la toca por momentos. [...] Se mueve su ánimo como un péndulo. Cuando llega al confín de la queja, a su Señor, esperanza y desesperación se unen y potencian. Y como Job resiste no se desintegran, retrocede, cae más bien en la soledad y se queda entonces en memoria: queda a solas con su memoria e invoca a la muerte, se entrega a ella por breves instantes en la más completa pasi- 
vidad. Va y viene entre dos puntos extremos: el clamor, la queja, la invocación, esperanza-desesperación, y la pasividad que anticipa el definitivo yacimiento (Zambrano: 360. La cursiva es nuestra).

$\mathrm{Y}$, ciertamente, parece que estos términos están describiendo la poesía de Jaime Sabines. Tomemos algún fragmento de uno de los poemas que conforman su libro Tarumba como ejemplo:

Quiero que me socorras, Señor, de tanta sombra que me rodea, de tanta hora que me asfixia. Quiero que me socorras. Nadie, de esta intranquila supervivencia de esta sobremuerte agotadora. Quiero que me hundas, Padre, de una vez para siempre en tu caldera de aceite.

Quiero, hijo, que me entierres bajo piedra y lodo, y una plancha de acero, sin un árbol.

$[\ldots]$

Quiero que el viento me recorra de norte a sur, de este a siempre.

Quiero crecer como una piedra regada todas las mañanas por el jardinero del sol (1983: 113-114).

Observamos cómo, casi espontáneamente, el poeta pasa de la desesperación y de la queja a la esperanza, y viceversa. Este tipo de transformaciones repentinas son muy propias del poeta Sabines. También en Tarumba leemos:

Entonces, sobre la tierra,

los hombres empiezan a volar como los ángeles.

En los mercados venden la felicidad.

[...]

Los gatos pasean del brazo a las ancianas ratas

y tú, delgado como una sonrisa, sueñas.

(Paréntesis: el antiguo mirar

de una mujer de negro.

Una mujer antigua,

Un negro sin tiempo.

Sonata en tiempo negro

escrita para mujer desvestida de negro.)

Esto se echó a perder,

Tarumba (1983: 102-103. La cursiva es nuestra). 
De la experiencia de Sabines con la muerte, que lo golpea incesantemente a través de sus seres más queridos, a través de la enfermedad y de la propia vejez, emergen las inevitables preguntas sobre el amor de Dios, sobre su justicia: "Dios, el manco de cien manos, / ciego de tantos ojos, / dulcísimo, impotente (1962: 273). El poeta chiapaneco, como Job, se encuentra terriblemente solo y desamparado: "De la cabeza me jalan, / con un anzuelo me jalan en las mañanas, / en las noches. / Del corazón me jalan / con una aguja, / me clavan un diente en el ojo. / Masco vidrio a la hora de dormir,/ cuando toca el viento las puertas / y quieren entrar los fantasmas" (1962: 221). Y prosigue Sabines:

¿Quién iba a decirme, quién iba a decirme nada?

¿Quién podría llorar por mí

echado en la pared, a estas horas?

Ay, qué largo,

qué interminable, ay,

qué ay $\tan$ hondo, tan sin cuerpo ni sangre,

qué lamento tan mío y tan tuyo, tan de nadie,

ay, ay, quiero llorarlo de un golpe,

quiero morirlo de una vez.

Yo te digo estas cosas para recordarlas,

no quiero que me recites nunca.

Yo quiero golpearte con mi dolor, quiero echarte al rostro mis lágrimas.

Quiero que despiertes, nada más,

para que veas que todo es inútil. ${ }^{6}$

$\mathrm{Y}$ es que en el mismo momento en que Jaime Sabines comprende que su propio sistema de justificaciones lo ahoga, intenta hacer una recapitulación que lo lleve a conocer la razón de su asfixia. Desea saber por qué sufre, por qué se desvela, qué es lo que realmente busca, por qué y para qué vive. De este modo se detiene ante la angustia de la existencia, es decir, ante lo misterioso y lo irracional, en ese espacio

\footnotetext{
${ }^{6}$ Idem. Resulta cuando menos anecdótico que, transcurrido bastante tiempo, Sabines llegara a escribir el siguiente poema titulado "Preocupación de Job", por supuesto en un tono entre irónico e incrédulo: "De pronto, me siento perseguido por la buena suerte. Todo me sale bien. Disfruto de salud, de amor, de dinero. ¿Qué hice? ¿qué debo hacer para merecerlo? / ¿Es una más de tus pruebas, Dios mío?” (Sabines 1991: 495).
} 
donde el hombre se encuentra en relación conflictiva con Dios porque no lo comprende, no lo siente cerca y ni siquiera sabe si existe o si sólo lo ha soñado. Así nos lo confirma el propio Sabines:

Yo podría definirme como un agnóstico. Como una gente que no cree en los términos tradicionales, ¿̨no? Y, sin embargo, estoy hablando de Dios constantemente desde que tenía diecinueve o veinte años. Dios es una palabra que me sirve para... para significar todo lo que ignoro, todo lo que desconozco, eso es Dios, ¿̨no? Dios es la medida de nuestra ignorancia. ${ }^{7}$

Ciertamente el término "Dios" surge con frecuencia en la obra de Jaime Sabines. Lo habitual es que lo haga como interrogante o como necesidad: "Y ahora sigo tu rastro, / olfateo como un sabueso cansado;" "Que el mundo sepa que lloramos aquí / por el amor crucificado y las vírgenes, / por nuestra hambre de Dios." También aparece como apoyo al desasosiego del poeta:

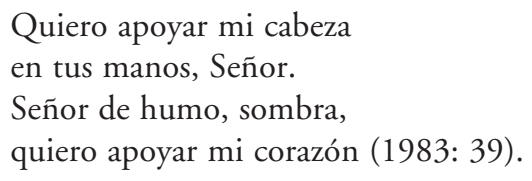

O consolándole de Él mismo, es decir, de esa falsa omnipotencia que parece ser Dios y sobre la que Sabines, compasivo, duda: "Dios mío, ¿qué Dios tienes tú? ¿quién es tu Dios padre, tu Dios abuelo? ¡Qué desamparado ha de estar el Dios primero, el último!” (1983: 246).

Por otro lado hallamos un Dios que no escucha, un Dios que "es sordo desde hace tiempo" (1983: 133), que no puede hacer nada para librar al hombre de la muerte ni de las desgracias cotidianas: “ $¡ Q u e ́$ naturaleza, qué Dios tan distante y tan ajeno!” (1983: 119). Por esta razón, cuando fallece el padre de Sabines, éste manifiesta: "el viejo sordo, sin hijos, / derrama su corazón en la copa de su vientre” (1962: 273).

\footnotetext{
7 Hay quien ha visto —erróneamente, creemos nosotros-, un exacerbado cristianismo en la obra de Jaime Sabines. No sólo hablamos de Guadalupe Flores Liera, también de Carlos González Salas: "Y luego veo con gusto que hablas de Cristo, que ante Él te defines; tú eres un cristiano de hueso colorado a pesar de tus pesares, amigo, poeta, gran Jaime Sabines" (González Salas 1996: 42).
} 
Asimismo, encontramos un Dios cruel que no siente compasión alguna por el ser humano:

Y es en vano llorar. Y si golpeas

las paredes de Dios, y si te arrancas

el pelo o la camisa,

nadie te oye jamás, nadie te mira (1983: 241).

Habría, incluso, un Dios que disfruta viendo sufrir al hombre: "Estírate o retuércete. Estás en el asador, sobre las brasas, para el hambre que tiene Dios este día" (1983: 131). Así, y aceptando esta situación de abandono por parte de Dios, Sabines llega a afirmar: "Líbreme Dios de mí / igual que me he librado de Dios." (1983: 195).

Sin embargo, en sus poemas finales, observamos una mayor simpatía hacia la figura de Dios, matizada ésta con gran sentido del humor. Podemos leer, por ejemplo, en el poema "Me encanta Dios":

Me encanta Dios. Es un viejo magnífico que no se toma en serio. A él le gusta jugar y juega, y a veces se le pasa la mano y nos rompe una pierna o nos aplasta definitivamente. Pero sucede porque es un poco cegatón y bastante torpe de las manos (1997: 421).

No obstante, y pese a este arrebato de cordialidad respecto a Dios, escribe en "Temas de la vejez y el cansancio," uno de sus últimos textos:

Todo me lo has dado, Señor.

Me diste a mi padre y la muerte de mi padre,

a mi madre y su muerte,

a mi hermano Juan y a su destino,

a Jorge, el verdadero y el fantasma, a mi mujer, Chepita, y a mis hijos, a mi cama me diste y a mis huesos que reclaman más tiempo.

Me diste todo, sí,

$y$ me he entregado

a vivir y a morir con calendario.

Sólo te pido que me dejes solo

a punto de las ocho porque es hora

de dormir. (1991: 489). 
En cuanto a la presencia del Nuevo Testamento en la obra de Jaime Sabines, hemos de decir que es prácticamente nula. Al revisar todos y cada uno de los poemas que componen sus libros, encontramos únicamente nueve ejemplos. Los dos primeros tienen su base en el episodio de la decapitación de Juan el Bautista, narrados en los evangelios de San Mateo y San Marcos:

Llegado un día oportuno, cuando Herodes en su cumpleaños ofrecía un banquete a sus magnates, y a los tribunos, y a los principales de Galilea, entró la hija de Herodías y, danzando, gustó a Herodes y a los comensales. El rey dijo a la muchacha: Pídeme lo que quieras y te lo daré. Y le juró: Cualquier cosa que me pidas te la daré, aunque sea la mitad de mi reino. Saliendo ella, dijo a su madre: ¿Qué quieres que pida? Ella le contestó: La cabeza de Juan el Bautista. Entrando luego con presteza, hizo su petición al rey, diciendo: Quiero que al instante me des en una bandeja la cabeza de Juan el Bautista. El rey, entristecido por su juramento y por los convidados, no quiso desairarla (San Mar$\cos 6,21-26)$.

\section{Así, leemos en Poemas sueltos:}

Siento que sube el nivel del vacío en mi vaso

y me place aniquilarme.

Mi cabeza, sobre una charola, en mis manos, predice el porvenir y guiña un ojo a la mujer bonita (1962: 217).

He aquí la cabeza del día, Salomé,

para que bailes delante de todos los ojos en llamas. (1962: 261)

Otros personajes del Nuevo Testamento que desfilan entre los versos de Sabines son los padres de Jesús: "Tú te abres y yo te penetro. / Tú eres María y yo soy José” (1997: 288) su amiga prostituta, María Magdalena: "¿Quién te tiene la mano, Magdalena, hundida en las almohadas?”, escribe el poeta chiapaneco. Y Lázaro, el resucitado, hermano de Marta y María de Betania, cuya historia es contada así por San Juan: "Diciendo esto, gritó con fuerte voz: Lázaro, sal fuera. Salió el muerto, ligado con fajas pies y manos, y el rostro envuelto en un sudario. Jesús les dijo: Soltadle y dejadle ir" (San Juan 11, 43-44). Y así por Sabines: 
¿Qué pensaría Lázaro cuando iba a morir por segunda vez? La segunda muerte ¿̨ue distinta de la primera como el lunes es distinto del martes? ¿A cuántas muertes tenemos derecho cada uno? Porque la vida es siempre la vida, pero la muerte... (1997: 275).

También Jesús resucitó al tercer día de su muerte. Sabines utiliza en Poemas sueltos esta imagen para hablar del hombre que, pese a todas sus desdichas y al dolor sufrido, debe sobreponerse y continuar viviendo:

Resucitado, para ti es la calle

y los árboles y la neblina

y el sol que pica

y la tarde friolenta que pide cama con mujer

y la noche que te recibe amorosa con un libro.

Para ti es también el amanecer de los que trabajan,

las fauces de las fábricas que se abren con ruido,

los relojes de las oficinas de mala digestión,

la estercolada y húmeda ternura de los establos,

el delantal de los almacenes y el garrote de seda,

el agua boricada de los despachos,

el fenol diario de la misa

y la triste sabiduría de los barrenderos.

[...]

Para que tú te entregues

se te están dando todas estas cosas;

para que dejes tu cuerpo usado

allí en el polvo donde estabas tendido bocabajo y llorabas;

para que te levantes a los treinta y tres años

y juegues con tus hijos y con todas las gentes

en el nombre del padre y del espíritu santo

y en el nombre del huérfano y del espíritu herido

y en el nombre de la gloria del juego del hombre (1962: 252-253).

Por otro lado, y ya para concluir, hallamos una mención a los cuatro jinetes del Apocalipsis: “Aquú, jinetes del Apocalipsis diario, / voy a trabarles las patas / con un cordón de seda! (1997: 289). A las célebres bienaventuranzas: "Bienaventurados los pacíficos, porque ellos serán llamados hijos de Dios" (San Mateo 5, 9), y a la conocida hipérbole del camello y la aguja: "Porque más fácil es que un camello pase por el ojo de una aguja que el que un rico entre en el reino de Dios" (San Lucas 18, 25). En esa línea, escribe Jaime Sabines con cierta ironía: 
Dichosos los bueyes porque son mansos, y las gallinas que son pisadas por la sombra del gavilán. Bienaventurados los que pasan por el ojo de una aguja el hilo del gran carrete de oro (1997: 303).

BiBLIOGRAFÍA

Biblia de Jerusalén. trad. Nacar y Colunga. Madrid: Biblioteca de Autores Cristianos, 1984.

Flores Liera, Guadalupe. Lo sagrado en la poesía de Jaime Sabines. México: Universidad Nacional Autónoma de México, Coordinación de Humanidades, 1996.

González Salas, Carlos. "Envío a Jaime Sabines". En Periódico de Poesía. México: primavera de 1996. 42.

LEÓn FeLIPE. El ciervo y otros poemas. Madrid: Visor, 1982.

Olivio Jiménez, José. (selecc. y pról.). Antología de la poesía hispano-americana contemporánea, 1914-1987. Madrid: Alianza, 1994.

Ortega, Julio. Antología de la poesía hispanoamericana actual. México: Siglo XXI, 1996.

Paz, Octavio. Los hijos del limo. Del romanticismo a la vanguardia. México: Seix Barral, 1987.

Sabines, Jaime. Nuevo recuento de poemas. México: Joaquín Mortiz / Planeta, 1983.

- Otro recuento de poemas (1950-1991). México: Joaquín Mortiz, 1991.

- Recuento de poemas. México: Universidad Nacional Autónoma de México, 1962.

Sabines, Jaime. Recuento de poemas 1950-1993. México: Joaquín Mortiz / Planeta, 1997.

Zambrano, María. El hombre y lo divino. Madrid: Siruela, 1991.

ZarebsKa, Carla. Jaime Sabines (algo sobre su vida). México: Paesano Printing, 1994. 